\title{
EXPERIMENTAL INVESTIGATION OF MULTI OBSTACLES IMPACT ON WEIR-GATE DISCHARGE STRUCTURE
}

\author{
Rafi M. Qasim ${ }^{1}$, Alya A. Mohammed ${ }^{1}$, Ihsan A. Abdulhussein ${ }^{1}$, Qusay A. Maatooq ${ }^{1}$ \\ ${ }^{1}$ Southern Technical University, Engineering Technical College, Iraq \\ Email: alayaalrefee@stu.edu.iq
}

\begin{abstract}
The flow over and under weir-gate structure that is placed inside a flume with obstacles downstream is studied experimentally. The distance between the first obstacle and weir-gate structure as well as the spacing between the obstacles are both considered constant. The goal of the present research paper is to characterize the interference between the weir-gate structure and the emerged square-shaped obstacle. The computation results show that the obstacles have a major role on dominating the trend between the several hydraulic variables. For instance, the relation between the discharge coefficient and upstream Froude number is adverse to the relation between the discharge coefficient and downstream Froude number. The increase of actual discharge leads to an increase in discharge coefficient. However, there is a dramatic trend in relation between the flow velocity at downstream and discharge coefficient. Another noticeable dramatic trend shown between the average downstream water depth and the discharge coefficient. In addition, it is found that there is a nonlinear trend in relation to Reynolds number and discharge coefficient. The present work discovered the impact of the flow across sectional area, which crosses the gate on the actual discharge and discharge coefficient, considering the number of obstacles at downstream regime with various obstacle thickness. Generally, any alteration in hydraulic response of weir-gate structure is attributed to the presence of obstacles at downstream of hydraulic regime, regardless of the number of obstacles and their dimensions.
\end{abstract}

Keywords: Flume, Gate, Hydraulic Structure, Obstacles, Weir.

\section{Introduction}

Weir-gate hydraulic structure can be described as a device to manage water resources in an open channel environment with a minimum variation in its functional requirements. The functional aspect relies on hydraulic variables and dimensional variables. Here, the interference between these variables have a direct effect on the device. Many research-papers have dealt with this issue. Qasim et al. (2020) carried out many experimental works to investigate the flow pattern which passed the weirgate structure and encountered obstacles at the open channel downstream. The obstacles are with or without rectangular opening, considering two different types of flow conditions. The investigation concentrated on the hydraulic and dimensional characteristics separately in order to assess the presence of the obstacle with and without an opening. From the results obtained, it is found that the obstacle with an opening produces a significant effect on the obtained value of composite hydraulic structure discharge coefficient [1]. In this research, an experimental work was carried out by Ibrahim (2017) to reveal the shapes of block influences on the flow pattern at the downstream of a radial wall. The tests illustrated that the blocks had a strong ability to limit the disconnected influence of the flow pattern at the downstream [2]. Samadi-Boroujeni et al. (2013) studied the hydraulic jump characteristics in flume which has a rectangular across the section over the triangular corrugated beds. Also, results illustrated that the folded bed affected the conjugate depths of the hop and the water powered hop length to be decreased by $25 \%$ and $54.7 \%$ separately [3]. The work of Lim et al. (2009) concentrated on the flow, the shear layers and the recirculation zones over and along the three streamwise cube surfaces [4]. Izadjoo and Shafai-Bejestan (2007) performed the tests of hydraulic jump on a bed of a trapezoidalshaped corrugated roughness. From the results they obtained that the shear force in a rough bed is higher than that in smooth bed [5]. Ead et al. (2000) carried out tests realized an open channel where the flow is noticed, turbulent, and discovered that the intense mixing resulting from the rough bed leads to important Reynolds shear stress and reduction in the velocity pattern above the corrugation [6]. The momentum approach is used by Raju et al (1983) to the case of vertical cylinders with rectangular channel. The vertical cylinder is considered an obstacle. They found a quadratic approximation for the break water. Good agreement is obtained between their solution and experiments [7]. 
The main aim of this research-paper is to identify the ability of multi-obstacle square models placed at the downstream regime of weir-gate hydraulic structure in changing the hydraulic characteristics of hydraulic structure. It should be mentioned that these cases represent a challenge which alters the hydraulic behaviour of hydraulic system.

\section{Fluid Concept}

Three different shapes of weir-gate hydraulic structure are used in the current experimental work. The procedure of the actual discharge calculation is shown below:

\subsection{Triangular weir - Ellipse Gate}

It aims to estimate the actual discharge that crosses the combined structure, when the flow condition is described free and the submerged of the actual discharge can be calculated from:

$$
Q_{\text {theor }}=Q_{w}+Q_{g}
$$

Theoretical discharge which crosses the weir can be calculated from (Streeter, 1983) [8].

$$
\begin{gathered}
Q_{w}=\frac{8}{15} \sqrt{2 g} \tan \frac{\emptyset}{2} h^{5 / 2} \\
Q_{\text {weir }}=\frac{8}{15} \sqrt{2 g} \tan \frac{\emptyset}{2} h^{5 / 2}
\end{gathered}
$$

Theoretical discharge which crosses the gate can be calculated by using the continuity equation, the continuity equation (Streeter, 1983) [8]:

$$
\begin{aligned}
& \mathrm{Q}=\mathrm{VA} \\
& Q_{g}=V A=\sqrt{2 g H} A
\end{aligned}
$$

(4)

$$
\begin{aligned}
& Q_{a c t}=c_{d} Q_{\text {theor }} \\
& Q_{a c t}=c_{d}\left[\frac{8}{15} \sqrt{2 g} \tan \frac{\emptyset}{2} h^{5 / 2}+\sqrt{2 g H} A\right]
\end{aligned}
$$

\subsection{Rectangular Weir - Ellipse Gates}

It aims to estimate the actual discharge that crosses the combined structure, when the flow condition is described free and the submerged of the actual discharge can be calculated from:

$$
Q_{\text {theor }}=Q_{w}+Q_{g}
$$

The theoretical discharge which crosses the weir can be calculated from (Streeter, 1983) [8].

$$
Q_{w}=\frac{2}{3} \sqrt{2 g} b h^{3 / 2}
$$

The theoretical discharge which crosses the gate can be calculated by using the continuity equation, the continuity equation (Streeter, 1983) [8]:

$$
\begin{gathered}
Q=\mathrm{VA} \\
Q_{g}=V A=\sqrt{2 g H} A \\
Q_{\text {gate }}=V A=\sqrt{2 g H} A \\
Q_{\text {act }}=c_{d} Q_{\text {theor }} \\
Q_{\text {act }}=c_{d}\left[\frac{2}{3} \sqrt{2 g} b h^{3 / 2}+\sqrt{2 g H} A\right]
\end{gathered}
$$

\subsection{Parabolic Weir - Ellipse Gates}

It aims to estimate the actual discharge that crosses the combined structure, when the flow condition is described free and the submerged of the actual discharge can be calculated from:

$$
Q_{\text {theo }}=Q_{W}+Q_{g}
$$

The theoretical discharge which crosses the weir can be calculated from (Bos,1989) [9].

$$
Q_{w}=\frac{\pi}{2} \sqrt{f g} h^{2}
$$

Theoretical discharge which crosses the gate can be calculated by using the continuity equation, the continuity equation (Streeter, 1983) [8]:

$$
\mathrm{Q}=\mathrm{VA}
$$

(16)

$$
Q_{g}=V A=\sqrt{2 g H} A
$$

$$
\begin{aligned}
& Q_{a c t}=c_{d} Q_{\text {theo }} \\
& Q_{a c t}=c_{d}\left[\frac{\pi}{2} \sqrt{f g} h^{2}+\sqrt{2 g H} A\right]
\end{aligned}
$$

For free flow condition

$$
H=d+y+h
$$

For submerged flow condition

$$
H=d+y+h-h_{d}
$$

Where H: upstream water depth, h: weir water head, $y$ : vertical distance between weir and gate, $d$ : 
gate opening height, A: gate cross section flow area, V: flow velocity, f: focal distance, b: Rectangular weir width, $\theta$ : Notch angle, g: acceleration due to gravity, Q_w :weir discharge, Q_g: Gate discharge, Q_theor: Theoretical discharge, Q_act: Actual discharge, c_d: Coefficient of discharge, the Reynolds number and Froude number are calculated by using the following equations $[10,11]$ :

$$
\begin{aligned}
& R_{e}=\frac{V h_{d}}{v} \\
& F_{r}=\frac{v}{\sqrt{g y}}
\end{aligned}
$$
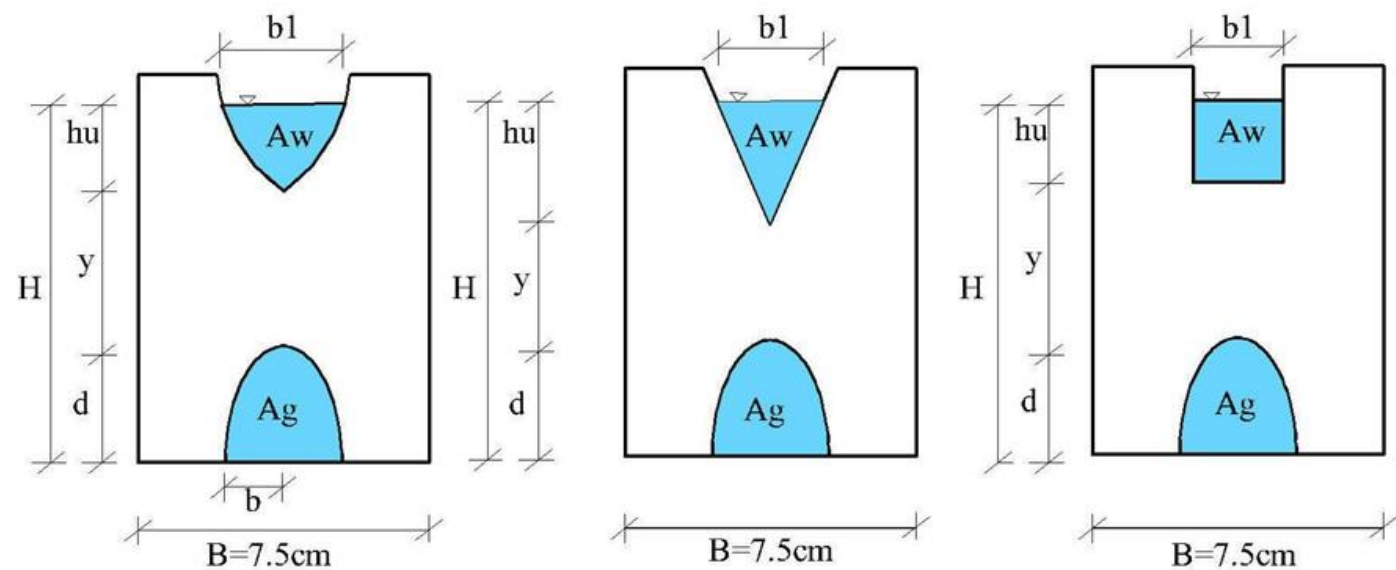

Figure (1): The different shapes of weir-gate structure.
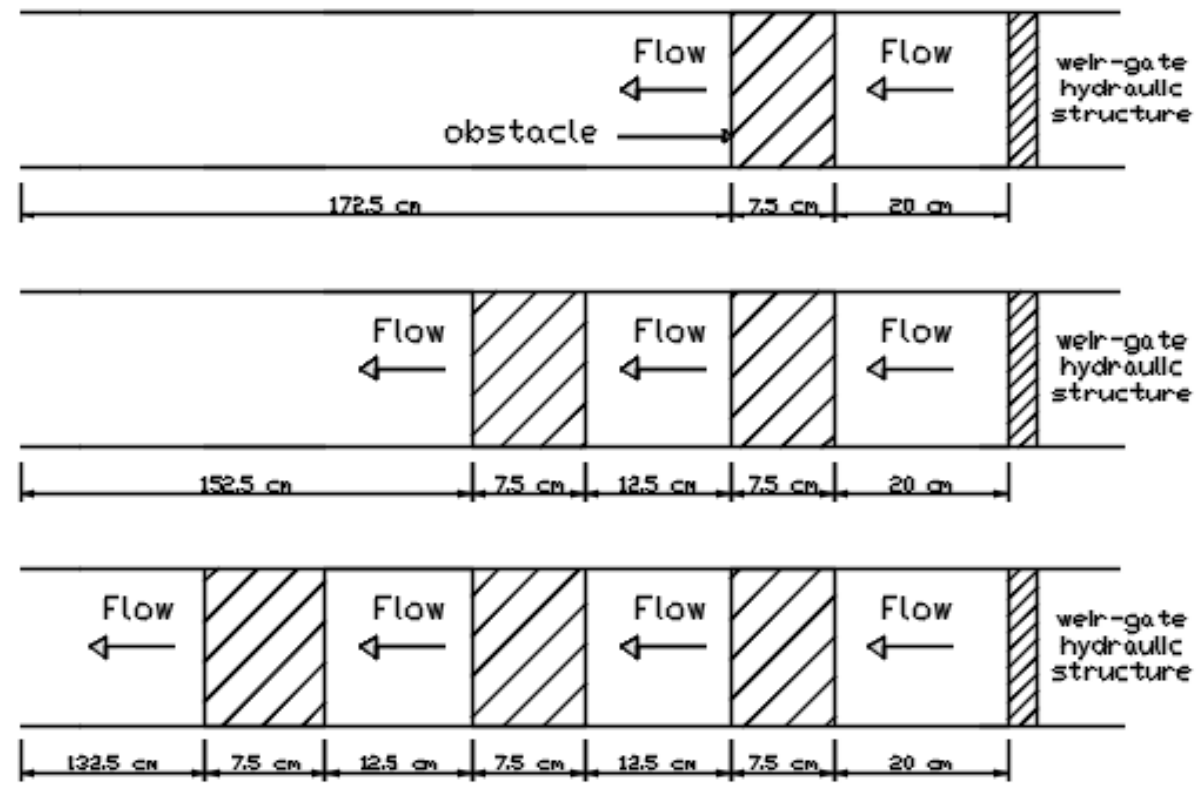

Figure (2): Location of Weir-Gate Structure and Obstacles

The bed of the flume is horizontal, fixed and flat. The actual discharge is measured by utilizing the volume method, while the depth of water is measured by utilizing the scale which is fixed at the flume wall. The weir-gate structure models are made from $5 \mathrm{~mm}$ wood sheet thickness.
This structure is beveled along all the edges at $\left(45^{\circ}\right)$ with sharp edges of thickness $(1 \mathrm{~mm})$. The blocked obstacle models are made by using wood material.

The blocks have square shape with dimensions $(7.5 \mathrm{~cm} \times 7.5 \mathrm{~cm})$ while the study adopted two 
different thickness and these are $1 \mathrm{~cm}$ and $0.5 \mathrm{~cm}$. The obstacle blocks are located at a specified distance which are equal to $20,40,60 \mathrm{~cm}$ at the downstream regime from the weir-gate structure, where the distance interval between the successive obstacles are equal to $20 \mathrm{~cm}$. In addition, the distance between the weir-gate structure and the first block's equal to $20 \mathrm{~cm}$.

Table (1): The Model Dimensions and Details of Different Shapes of weir and Ellipse Gate

\begin{tabular}{|c|c|c|c|c|c|c|c|c|c|}
\hline $\begin{array}{l}\text { Model } \\
\text { No. }\end{array}$ & Weir Shape & $\begin{array}{c}\text { Gate } \\
\text { shape }\end{array}$ & $\begin{array}{c}\mathrm{h} \\
(\mathrm{cm})\end{array}$ & $\begin{array}{c}\mathrm{y} \\
(\mathrm{cm})\end{array}$ & $\begin{array}{c}\mathrm{d} \\
(\mathrm{cm})\end{array}$ & $\begin{array}{c}\mathrm{H} \\
(\mathrm{cm})\end{array}$ & $y / H$ & $A_{g}\left(\mathrm{~cm}^{2}\right)$ & $A_{g} / B H$ \\
\hline $1--1$ & Rectangular & Ellipse & 1 & 4.5 & 2.5 & 8 & 0.5625 & 4.908 & 0.0818 \\
\hline $1--2$ & Rectangular & Ellipse & 2 & 4.5 & 2.5 & 9 & 0.5000 & 4.908 & 0.0727 \\
\hline $1--3$ & Rectangular & Ellipse & 3 & 4.5 & 2.5 & 10 & 0.4500 & 4.908 & 0.0654 \\
\hline $2--1$ & Triangular & Ellipse & 1 & 3.5 & 2.5 & 7 & 0.5000 & 4.909 & 0.0935 \\
\hline $2--2$ & Triangular & Ellipse & 2 & 3.5 & 2.5 & 8 & 0.4375 & 4.909 & 0.0818 \\
\hline $2--3$ & Triangular & Ellipse & 3 & 3.5 & 2.5 & 9 & 0.3889 & 4.909 & 0.0727 \\
\hline $3--1$ & Rectangular & Ellipse & 1 & 4 & 3 & 8 & 0.5000 & 7.068 & 0.1178 \\
\hline $3--2$ & Rectangular & Ellipse & 2 & 4 & 3 & 9 & 0.4444 & 7.068 & 0.1047 \\
\hline $3--3$ & Rectangular & Ellipse & 3 & 4 & 3 & 10 & 0.4000 & 7.068 & 0.0942 \\
\hline $4--1$ & Parabolic & Ellipse & 1 & 4.5 & 2.5 & 8 & 0.5625 & 4.908 & 0.0818 \\
\hline $4--2$ & Parabolic & Ellipse & 2 & 4.5 & 2.5 & 9 & 0.5000 & 4.908 & 0.0727 \\
\hline $4--3$ & Parabolic & Ellipse & 3 & 4.5 & 2.5 & 10 & 0.4500 & 4.908 & 0.0654 \\
\hline $5--1$ & Triangular & Ellipse & 1 & 3 & 3 & 7 & 0.4286 & 7.069 & 0.1346 \\
\hline $5--2$ & Triangular & Ellipse & 2 & 3 & 3 & 8 & 0.3750 & 7.069 & 0.1178 \\
\hline $5--3$ & Triangular & Ellipse & 3 & 3 & 3 & 9 & 0.3333 & 7.069 & 0.1047 \\
\hline $5--4$ & Triangular & Ellipse & 4 & 3 & 3 & 10 & 0.3000 & 7.069 & 0.0942 \\
\hline $6--1$ & Parabolic & Ellipse & 1 & 4 & 3 & 8 & 0.5000 & 7.068 & 0.1178 \\
\hline $6--2$ & Parabolic & Ellipse & 2 & 4 & 3 & 9 & 0.4444 & 7.068 & 0.1047 \\
\hline $6--3$ & Parabolic & Ellipse & 3 & 4 & 3 & 10 & 0.4000 & 7.068 & 0.0942 \\
\hline
\end{tabular}

Table (1) shows the selected dimension of weirgate structure. Figure (1) illustrates the shapes of weir-gate structure and figure (2) illustrates the entire hydraulic system which includes both the weir-gate structure and blocks. In each experiment, the following are measured: upstream water depth, water head above weir sharp crest, actual discharge and water depth at flume downstream. In brief, the current work deals with submerged flow.

\section{Results and Discussion}

Water flow analysis between weir-gate structure and obstacles are performed in laboratory to investigate the effect of using multi - obstacles.

Figure (3) shows the scatter distribution of discharge coefficient for various downstream Froude number, considering various numbers and thickness of obstacle. It is observed that the downstream Froude number decreases with the increase in number of obstacles and leads to increases in discharge coefficient. The discharge coefficient and downstream Froude number distribution values are based on number and dimension (length, width and thickness) of obstacles, especially the thickness.

The obstacles spacing is constant, so the spacing has no direct impact on the distribution. Also, it is obvious from this figure, that the maximum discharge coefficient value is equal to one regardless of the number of obstacles.

Figure (4) shows the scatter distribution of discharge coefficient for various upstream Froude numbers considering various numbers and thickness of obstacle.

It is observed that the upstream Froude number increases with the increase in number of obstacles and leads to the increases in discharge coefficient. The discharge coefficient and upstream Froude number distribution values are more sensitive to the number of obstacles and obstacle dimensions (length, width and thickness), especially the thickness. The obstacle's spacing is constant, so the spacing has no direct impact on the distribution. Also, it is obvious that the maximum discharge 
coefficient value's equal to one regardless of the number of obstacles at downstream region.

Figure (5) shows the scatter distribution of discharge coefficient for various downstream flow velocity considering various numbers and thickness of obstacle.
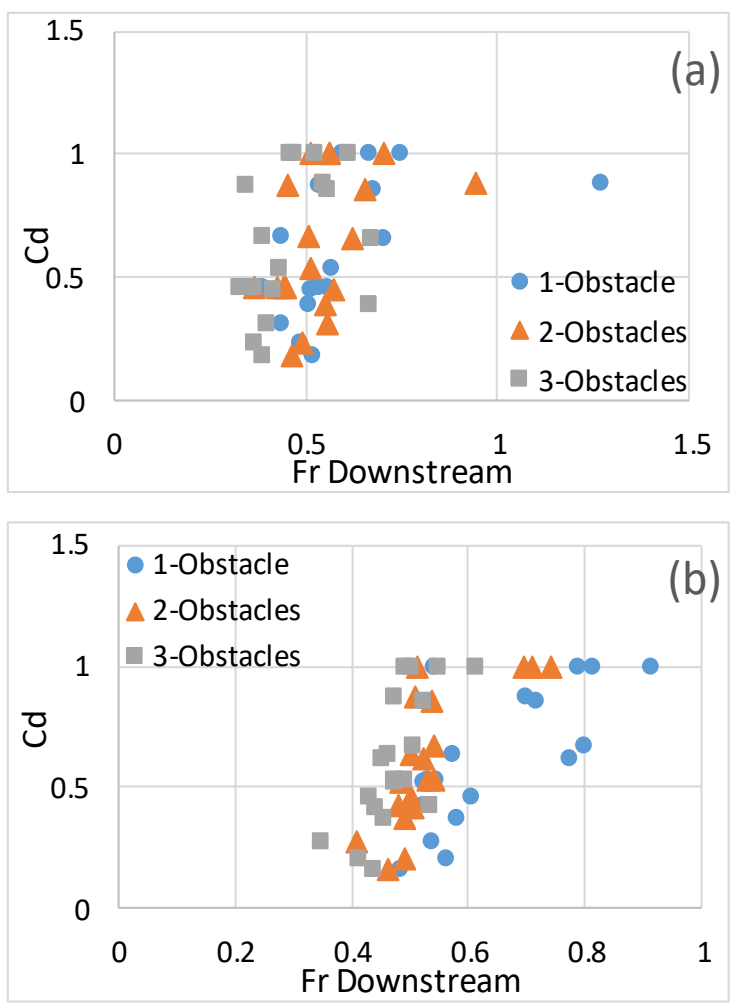

Figure (3): The relation between discharge coefficient and downstream Froude number, (a) $t=1 \mathrm{~cm},(b)$ $t=0.5 \mathrm{~cm}$

From this figure, it is obvious that the increasing number of obstacles causes decreasing in the downstream flow velocity and discharge coefficient. In general, there is no direct relation between discharge coefficient and downstream flow velocity.

Also, this figure shows a complex distribution of discharge coefficient and downstream flow velocity. This distribution occurs due to the interferences between the hydraulic variables that control the discharge coefficient and downstream flow velocity and the interaction between the over flow and under flow velocities which is reflected on the trend of relation between discharge coefficient and downstream flow velocity.

Figure (6) illustrates the scatter distribution of discharge coefficient for different downstream Reynold numbers considering various number of obstacle.

It is clear from the figure that as the number of obstacles increases the Reynolds decreased number. The decrease in Reynold numbers occurs due to the reduction in water depth near or above the obstacles. This behavior will be reflected on the downstream flow velocity and leads to the reduction in Reynold numbers, moreover, Reynold numbers are directly proportional with the water depth and flow velocity.
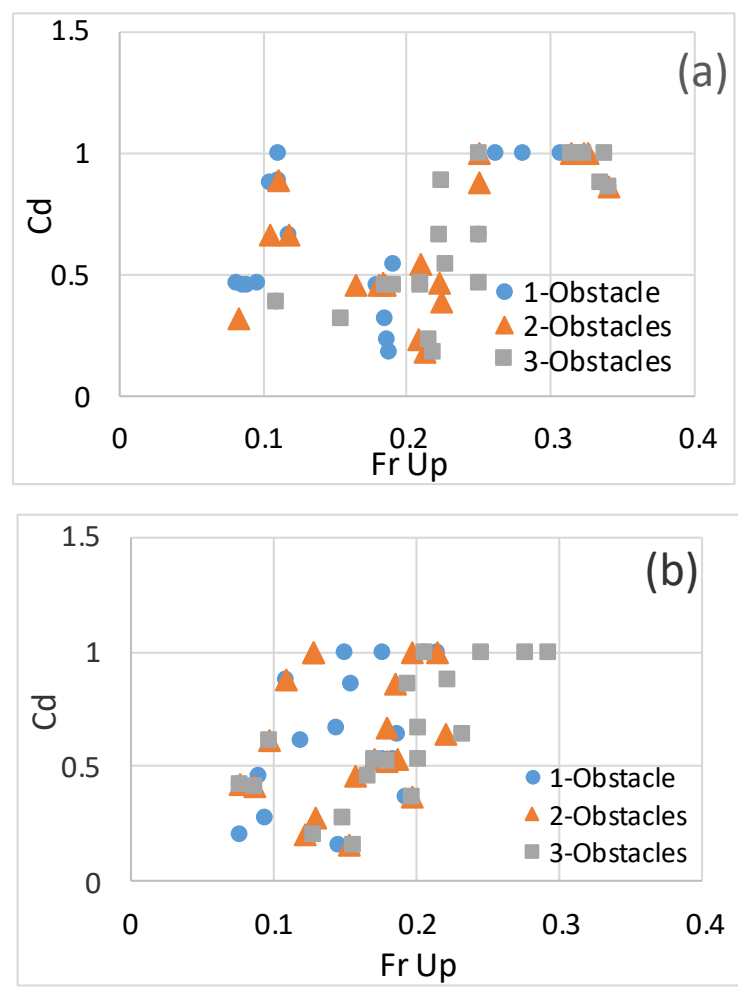

Figure (4): The relation between discharge coefficient and upstream Froude number, (a) $t=1 \mathrm{~cm},(b) t=0.5 \mathrm{~cm}$ 

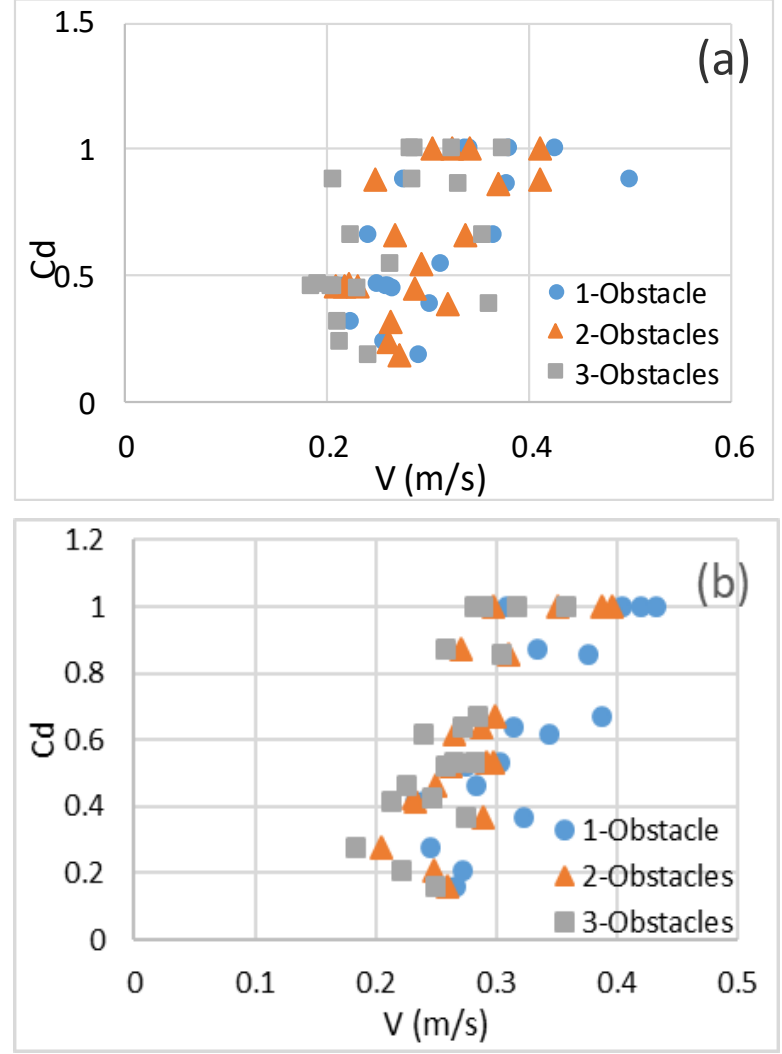

Figure (5): The relation between discharge coefficient and Flow velocity at downstream, (a) $t=1 \mathrm{~cm},(b) t=0.5 \mathrm{~cm}$

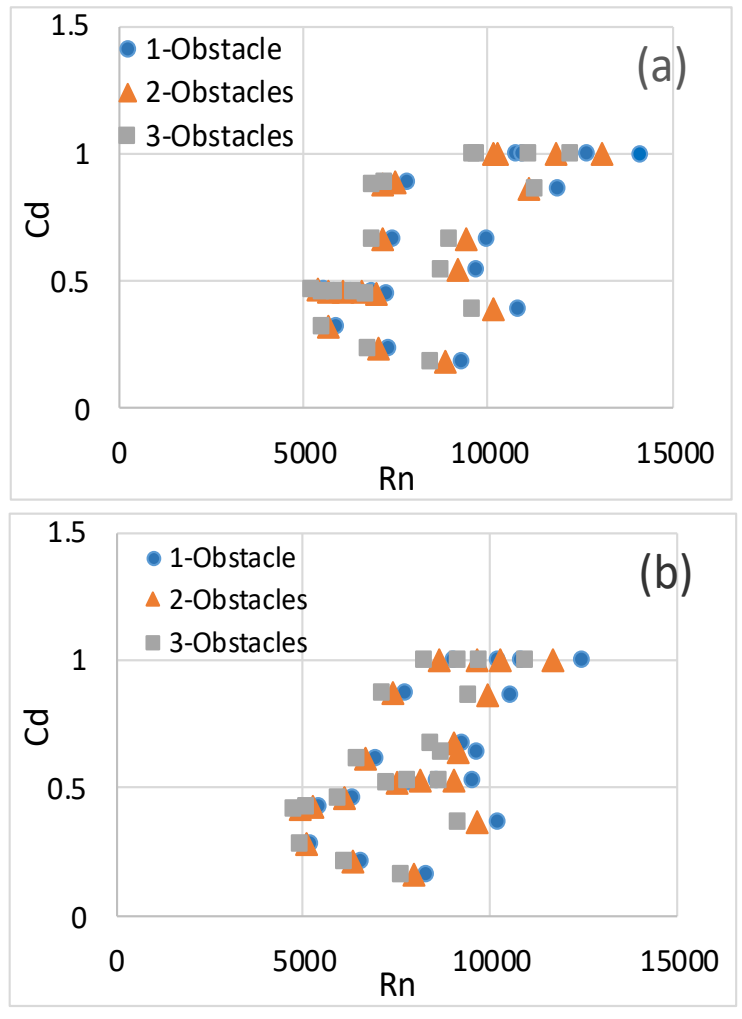

Figure (6): The relation between discharge coefficient and Reynolds number, (a) $t=1 \mathrm{~cm}$, (b) $t=0.5 \mathrm{~cm}$

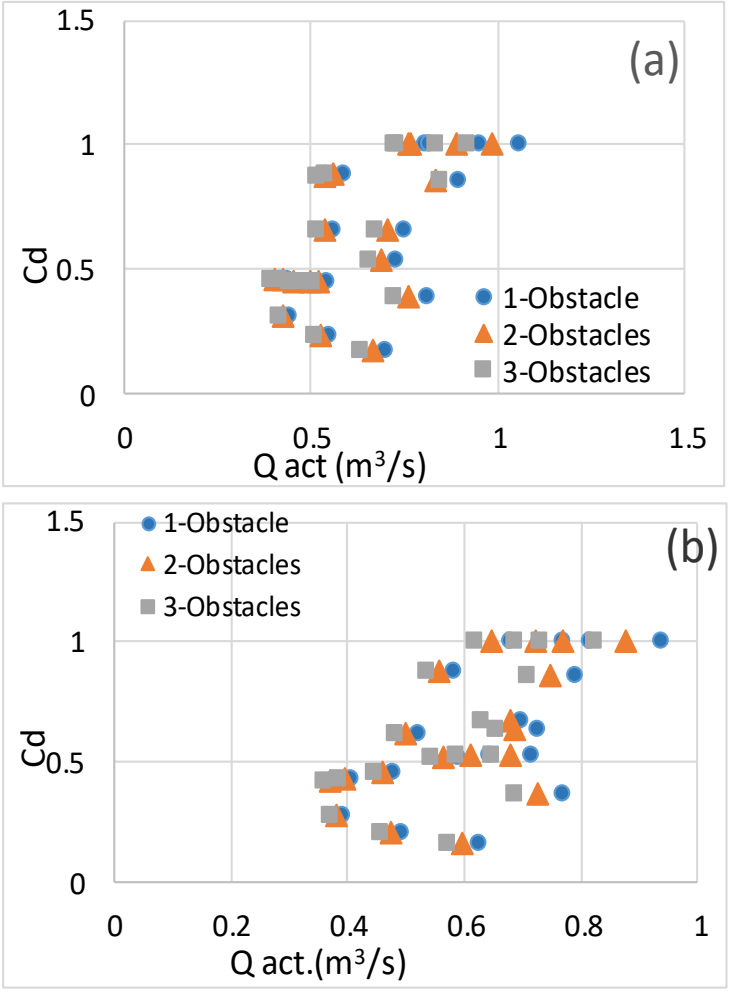

Figure (7): The relation between discharge coefficient and actual discharge, (a) $t=1 \mathrm{~cm},(\mathrm{~b})$ $t=0.5 \mathrm{~cm}$

Regarding any change in downstream water depth and flow velocity will be reflected also on Reynold number values. However, it should refer to the number of obstacles and their dimensions, which have major impact on the relation between Reynold numbers and discharge coefficient. Likewise, it is observed that the discharge coefficient decreases with increases in obstacles. This result from the fact that the interaction between over flow velocity and under flow velocity is affected by the obstacle numbers and dimensions.

Generally, there is no direct relation between the Reynold numbers and the discharge coefficient.

Figure (7) shows the scatter distribution of discharge coefficient for various actual discharge, considering various numbers and thickness of obstacles. It is observed from this figure that any increase in the actual discharge will be reflected on the discharge coefficient and visa versa. This is due to the direct proportionality between them, regardless of the number of obstacles and their dimensions. Also, it is observed that, as the number of obstacles increases, the actual discharge and discharge coefficient will be decreased, respectively. 


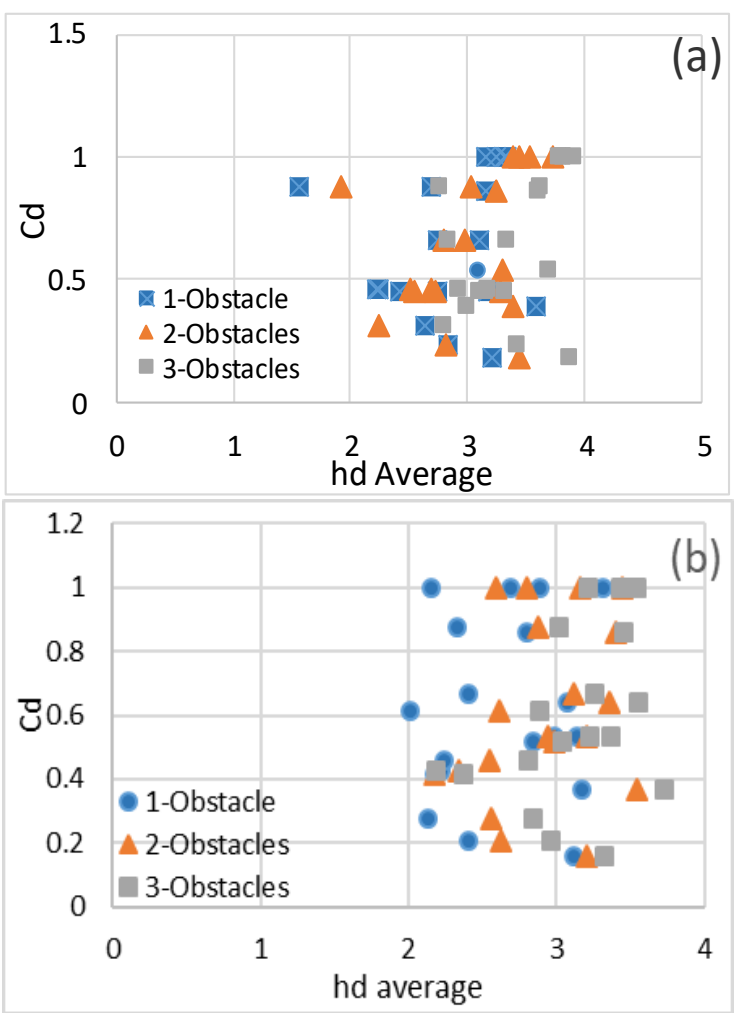

Figure (8): The relation between discharge coefficient and average water depth at downstream, (a) $t=1 \mathrm{~cm}$, (b) $t=0.5 c$

Figure (8) shows the scatter distribution of discharge coefficient for various average downstream water depth, considering various numbers and thickness of obstacle.

Table 2 The relation among the ratio $\mathrm{Ag} / \mathrm{BH}$, actual discharge and discharge coefficient $(\mathrm{t}=1 \mathrm{~cm})$

\begin{tabular}{|c|c|c|c|c|c|c|c|c|}
\hline \multicolumn{4}{|c|}{$\mathrm{A}_{\mathrm{g}} / \mathrm{BH}$} & \multicolumn{3}{c|}{$\mathrm{Q}(\mathrm{L} / \mathrm{sec})$} & \multicolumn{3}{c|}{$\mathrm{Cd}$} \\
\hline $\begin{array}{c}\text { One } \\
\text { Obstacle }\end{array}$ & $\begin{array}{c}\text { Two } \\
\text { Obstacle }\end{array}$ & $\begin{array}{c}\text { Three } \\
\text { Obstacle }\end{array}$ & $\begin{array}{c}\text { One } \\
\text { Obstacle }\end{array}$ & $\begin{array}{c}\text { Two } \\
\text { Obstacle }\end{array}$ & $\begin{array}{c}\text { Three } \\
\text { Obstacle }\end{array}$ & $\begin{array}{c}\text { One } \\
\text { Obstacle }\end{array}$ & $\begin{array}{c}\text { Two } \\
\text { Obstacle }\end{array}$ & $\begin{array}{c}\text { Three } \\
\text { Obstacle }\end{array}$ \\
\hline 0.148 & 0.157 & 0.166 & 0.726 & 0.689 & 0.656 & 0.540 & 0.540 & 0.540 \\
\hline 0.178 & 0.182 & 0.182 & 0.514 & 0.495 & 0.478 & 0.454 & 0.454 & 0.454 \\
\hline 0.118 & 0.201 & 0.220 & 0.438 & 0.424 & 0.412 & 0.459 & 0.459 & 0.459 \\
\hline 0.106 & 0.119 & 0.119 & 0.952 & 0.890 & 0.836 & 1.000 & 1.000 & 1.000 \\
\hline 0.123 & 0.136 & 0.139 & 0.806 & 0.761 & 0.721 & 1.000 & 1.000 & 1.000 \\
\hline 0.082 & 0.145 & 0.177 & 0.560 & 0.538 & 0.517 & 0.875 & 0.875 & 0.875 \\
\hline 0.150 & 0.163 & 0.165 & 0.699 & 0.665 & 0.634 & 0.178 & 0.178 & 0.178 \\
\hline 0.175 & 0.189 & 0.192 & 0.548 & 0.527 & 0.507 & 0.231 & 0.231 & 0.231 \\
\hline 0.201 & 0.118 & 0.178 & 0.441 & 0.427 & 0.414 & 0.314 & 0.314 & 0.314 \\
\hline 0.157 & 0.163 & 0.163 & 1.060 & 0.984 & 0.917 & 1.000 & 1.000 & 1.000 \\
\hline 0.131 & 0.131 & 0.131 & 0.896 & 0.836 & 0.847 & 0.859 & 0.859 & 0.859 \\
\hline 0.145 & 0.082 & 0.145 & 0.560 & 0.536 & 0.515 & 0.662 & 0.662 & 0.662 \\
\hline 0.065 & 0.113 & 0.113 & 0.820 & 0.769 & 0.728 & 1.000 & 1.000 & 1.000 \\
\hline 0.105 & 0.171 & 0.178 & 0.545 & 0.523 & 0.503 & 0.450 & 0.450 & 0.450 \\
\hline 0.118 & 0.178 & 0.209 & 0.471 & 0.454 & 0.439 & 0.454 & 0.454 & 0.454 \\
\hline 0.135 & 0.236 & 0.255 & 0.419 & 0.405 & 0.393 & 0.460 & 0.460 & 0.460 \\
\hline 0.065 & 0.106 & 0.065 & 0.811 & 0.761 & 0.721 & 0.388 & 0.388 & 0.388 \\
\hline 0.073 & 0.073 & 0.111 & 0.750 & 0.708 & 0.673 & 0.660 & 0.660 & 0.660 \\
\hline
\end{tabular}

Table 3 The relation among the ratio $\mathrm{Ag} / \mathrm{BH}$, actual discharge and discharge coefficient $(t=0.5 \mathrm{~cm})$ 


\begin{tabular}{|c|c|c|c|c|c|c|c|c|}
\hline \multicolumn{3}{|c|}{$\mathrm{Ag}_{\mathrm{g}} / \mathrm{BH}$} & \multicolumn{3}{c|}{$\mathrm{Q}(\mathrm{L} / \mathrm{sec})$} & \multicolumn{3}{c|}{$\mathrm{Cd}$} \\
\hline $\begin{array}{c}\text { One } \\
\text { Obstacle }\end{array}$ & $\begin{array}{c}\text { Two } \\
\text { Obstacle }\end{array}$ & $\begin{array}{c}\text { Three } \\
\text { Obstacle }\end{array}$ & $\begin{array}{c}\text { One } \\
\text { Obstacle }\end{array}$ & $\begin{array}{c}\text { Two } \\
\text { Obstacle }\end{array}$ & $\begin{array}{c}\text { Three } \\
\text { Obstacle }\end{array}$ & $\begin{array}{c}\text { One } \\
\text { Obstacle }\end{array}$ & $\begin{array}{c}\text { Two } \\
\text { Obstacle }\end{array}$ & $\begin{array}{c}\text { Three } \\
\text { Obstacle }\end{array}$ \\
\hline 0.145 & 0.139 & 0.139 & 0.7149 & 0.679 & 0.647 & 0.532 & 0.5317 & 0.532 \\
\hline 0.163 & 0.163 & 0.163 & 0.588 & 0.564 & 0.542 & 0.520 & 0.520 & 0.520 \\
\hline 0.118 & 0.118 & 0.118 & 0.406 & 0.394 & 0.383 & 0.426 & 0.426 & 0.426 \\
\hline 0.091 & 0.093 & 0.102 & 0.938 & 0.877 & 0.824 & 1.000 & 1.000 & 1.000 \\
\hline 0.102 & 0.073 & 0.121 & 0.816 & 0.770 & 0.729 & 1.000 & 1.000 & 1.000 \\
\hline 0.091 & 0.082 & 0.142 & 0.680 & 0.648 & 0.619 & 1.000 & 1.000 & 1.000 \\
\hline 0.137 & 0.141 & 0.143 & 0.624 & 0.596 & 0.571 & 0.158 & 0.158 & 0.158 \\
\hline 0.105 & 0.143 & 0.147 & 0.491 & 0.474 & 0.458 & 0.207 & 0.207 & 0.207 \\
\hline 0.139 & 0.171 & 0.189 & 0.392 & 0.381 & 0.371 & 0.279 & 0.279 & 0.279 \\
\hline 0.121 & 0.137 & 0.141 & 0.791 & 0.748 & 0.709 & 0.859 & 0.859 & 0.859 \\
\hline 0.087 & 0.101 & 0.109 & 0.698 & 0.681 & 0.630 & 0.670 & 0.670 & 0.670 \\
\hline 0.093 & 0.082 & 0.082 & 0.521 & 0.500 & 0.482 & 0.616 & 0.616 & 0.616 \\
\hline 0.093 & 0.101 & 0.104 & 0.768 & 0.723 & 0.687 & 1.000 & 1.000 & 1.000 \\
\hline 0.152 & 0.157 & 0.165 & 0.644 & 0.612 & 0.586 & 0.531 & 0.531 & 0.531 \\
\hline 0.118 & 0.171 & 0.178 & 0.478 & 0.460 & 0.445 & 0.460 & 0.460 & 0.460 \\
\hline 0.135 & 0.135 & 0.135 & 0.380 & 0.369 & 0.359 & 0.417 & 0.417 & 0.417 \\
\hline 0.099 & 0.101 & 0.101 & 0.769 & 0.725 & 0.688 & 0.369 & 0.369 & 0.369 \\
\hline 0.101 & 0.113 & 0.117 & 0.726 & 0.686 & 0.654 & 0.640 & 0.640 & 0.640 \\
\hline
\end{tabular}

1- The relation between upstream Froude

Both of them, the average water depth and discharge coefficient are considered independent variables because there is no direct relation between them. On the other hand, it is shown that both of the variables increase simultaneously with an increase in obstacle numbers, regardless of the obstacle thickness and spacing.

Tables 2 and 3 show the relation among the ratio $\mathrm{Ag} / \mathrm{BH}$, actual discharge and discharge coefficient, considering the obstacle numbers for different obstacle thickness. In general, when the cross sectional area of the gate increases, the discharge quantity which crosses the gate will be increased and any fluctuation in discharge will be associated with the interaction between the over flow discharge of the weir and under flow discharge from gate. However, the presence of obstacles will alter the general behavior of the discharge quantity, passing through the weir-gate structure. Also, the presence of the obstacles leads to the decrease in discharge quantity and this decrease rises with the increase in number of obstacles. In addition, any change in discharge quantity will be reflected on the discharge coefficient of the weir-gate structure.

\section{Conclusions}

The following noticeable points are apparent in the present paper: number and discharge coefficient is considered adversal to the relation between the downstream Froude number and discharge coefficient.

2- The number of obstacles has a direct impact on the hydraulic variables which dominate, the weirgate hydraulic structure operation. Also, the dimensions of obstacles, especially the thickness that has the same impact on hydraulic variables while the spacing will not have any impact.

3- The interaction between the over flow velocity and under flow velocity always controls the hydraulic variables, regardless of the presence and number of obstacles.

4- The number of obstacles at downstream regime has a direct impact on average downstream water depth.

5- Any increase in actual discharge will be reflected on discharge coefficient, regardless of the number of obstacles due to the direct proportionality between them.

6- The complex relation between the flow velocity at the downstream regime and discharge coefficient is resulting from both of them, being considered as independent hydraulic variables. 
7- The relation between the Reynold number and discharge coefficient will be affected by the number and thickness of the obstacles.

8- The flow cross-section area of the gate has a major impact on the discharge quantity and coefficient of discharge. Also, the flow area will be affected by the number of obstacles.

\section{References}

[1] Qasim, R.M., ABDULHUSSEIN, I.A., MOHAMMED, A.A., MAATOOQ, Q.A., The effect of the obstacle on the hydraulic response of the composite hydraulic structure. INCAS BULLETIN, Volume 12, Issue 3/ 2020, pp. 159 - 172.

[2] Ibrahim, M.M., Improve the efficiency of stilling basin using different types of blocks. American Journal of Engineering Research (AJER), Volume- 6, Issue-8, pp-295-304, 2017.

[3] H. Samadi-Boroujeni, M. Ghazali, B. Gorbani, R. Fattahi Nafchi, Characteristics of hydraulic jump on corrugated beds, Canadian Journal of Civil Engineering, volume 40 issue 9 on (September 2013): 841-847.

[4] Lim HC, Thomas T, Castro IP (2009) Flow around a cube in a turbulent boundary layer: LES and experiment. J Wind Eng Ind Aerodyn 97(2):96-109.

[5] Izadjoo, F. and M. Shafai-Bejestan, Corrugated bed hydraulic jump stilling basin. J. Applied Sci. , 7:1164-1169, 2007.

[6] Ead, S.A., N. Rajaratnam and C. Katopoodis, Turbulent open-channel flow in circular corrugate culvert. J. Hydraulic Eng. ASCE., 126:750-757, 2000.

[7] Ranga Raju, K.G., Rana, O. P. S., Asawa, G.L. \& Pillai, A. S. N., Rational assessment of blockage effect in channel flow past smooth circular cylinders, Journal of Hydraulic Research 21: 289-302, 1983.

[8] V. L. Streeter, and E. B, Wylie, Fluid Mechanics. First SI Metric Edition, 1983.

[9] BOS, M. G. (1989). Discharge Measurement Structures. 3rd Edition International Institute for Land Reclamation and Improvement/ Wageningen, The Netherlands.

[10] Fox, R. W. and McDonald, A. T. (1994) Introduction to Fluid Mechanics, Fourth Edition, SI version Copyright (C) John Wiley and Sons, Inc,.

[11] A.M. Negm, M. AL- Brahim, A, A. ALHamid, A, Combined-Free Flow Over Weirs and Below Gates, J. Hydraul. Res. 40 (2002) 1-7. 